\title{
Los logos de las marcas ONGD. Sentido y evolución
}

\author{
Pilar Alfonso EscudeR ${ }^{1}$ \\ Universidad de Valencia
}

Recibido: $10 / 11 / 2014$

Aceptado: 11/01/2015

\begin{abstract}
Resumen
La hipótesis inicial de este artículo es que, desde mediados de los años noventa, la lógica de marca se ha extendido al ámbito de la cooperación y de la ayuda humanitaria. Que en las últimas décadas las grandes ONGD han devenido marcas postmodernas. A manera de ejemplo, hemos estudiado los logos aparecidos en los anuncios de televisión de cinco de estas organizaciones: Intermón Oxfam, Médicos Sin Fronteras, Anesvad, Ayuda en Acción y África Directo. Sin duda, el logo es el primer elemento a considerar para establecer un posicionamiento de marca porque en un logo, además de la identidad visual, se anticipan metonímicamente los relatos y los valores que sustenten la marca, bien sea una marca estrictamente comercial, bien sean las nuevas marcas de cuño solidario.
\end{abstract}

Palabras clave: ONGD, posicionamiento de marca, postmodernidad, logo, solidaridad.

\section{NGDO brand logos. Sense and evolution}

\begin{abstract}
The initial hypothesis of this article states that from the middle nineties, branding has extended to the field of cooperation and human aid, and that in the last decades, the big NGDOs have become postmodern brands. The logos of five of these NGDOs (Intermón Oxfam, Médicos Sin Fronteras, Anesvad, Ayuda en Acción and África Directo) shown on TV advertisements have been analysed. Logos are the first elements to be considered in order to establish brand placing. Besides visual identity, logos bring metonymically forward stories and values that support brands, both tradicional trade brands and new charity brands.

Keywords: Non-Governmental Development Organization (NGDO), Brand placing, Postmodernism, Logo, Charities.

${ }^{1}$ El análisis que proponemos forma parte de una investigación más amplia desarrollada en nuestra tesis doctoral titulada EL NEORELAT SOLIDARI. La publicitat televisiva de les ONGD (1986-2010) $\neg$ defendida en la Universidad de València en septiembre de 2013 en donde hemos aplicado un análisis sociosemiótico a 184 anuncios de televisión realizados por nueve ONGD: las cinco mencionadas arriba más Cruz Roja, Unicef, Manos Unidas e Intervida. E-mail: piales@alumni.uv.es
\end{abstract}




\section{Introducción}

A nuestro entender, la gran relevancia social y comunicativa de las organizaciones no gubernamentales para el desarrollo (ONGD), a lo largo de estas últimas décadas, exige una reflexión académica intensa y continuada, un esfuerzo por definir y delimitar sus estrategias de comunicación. El propósito de este artículo no es otro que sumarse a esa reflexión tan necesaria.

Nuestra hipótesis inicial es que la lógica de marca se ha extendido al ámbito de la cooperación y de la ayuda humanitaria, que la llamada diseminación social de la marca (Semprini, 2006) ha llegado también a las ONGD. A partir de esta hipótesis, nos proponemos analizar los diferentes logos utilizados por cinco ONGD en sus anuncios de televisión, desde finales de los años ochenta. Analizaremos los logos de Intermón Oxfam (IO), Médicos Sin Fronteras (MSF), Ayuda en Acción (AenA), Anesvad y África Directo (AD).

Resulta evidente la heterogeneidad de la muestra: dos organizaciones especializadas en cooperación y ayuda al desarrollo (Intermón Oxfam y África Directo); dos organizaciones de asistencia sanitaria (Médicos sin fronteras y Anesvad); y, finalmente, una organización especializada en el apadrinamiento de niños del Tercer Mundo (Ayuda en Acción). Pensamos que dicha heterogeneidad puede propiciar una visión más amplia de la cuestión.

A lo largo de las últimas décadas, el término marca ha dejado de ser un concepto básicamente comercial o empresarial y se ha expandido al universo de la comunicación. De forma que las marcas han pasado a ser un mecanismo fundamental para la transmisión de sentido. En nuestros días todo es, o quiere ser, una marca. Los equipos de fútbol, los museos, las universidades, los partidos políticos... incluso los países quieren ser una marca. Pero, ¿qué es una marca? Seguiremos el enfoque socio-semiótico que concibe la marca como "una construcción de sentido basada en sistemas simbólicos y en relatos" (Semprini, 2006:247).

En los últimos años, han sido numerosas las publicaciones (Lucerga, 2005; Gómez Gil, 2005; Nos Aldás, 2007; Saiz Echezarreta, 2009) que han apuntado la evolución de las ONGD hacia la lógica y las estrategias de marca. En las páginas siguientes nos preguntaremos en qué sentido podemos hablar de la marca ONGD y de las grandes ONGD como marcas. ¿Son las grandes ONGD una muestra más de la extensa y compleja diseminación social de la marca postmoderna?

A modo de ejemplo, analizaremos las estrategias seguidas por las ONGD seleccionadas en su búsqueda de un posicionamiento de marca. Y lo haremos a partir del estudio de los logos utilizados en sus anuncios de televisión, a lo largo de los últimos veinticinco años.

\section{Las ONGD como marcas}

A finales del siglo XIX, cuando se crearon algunas de las grandes marcas de nuestros días, una marca tenía como función comunicar la existencia de un determinado producto, darle nombre y aportar información sobre lo que el producto ofrecía a los consumidores. En el año 1991, Kapferer i Thoening (Codeluppi, 1996) identificaron las seis funciones principales de la marca. A saber: 
- La función de identificación del producto, en lo que se refiere a sus características y atributos.

- La función de orientación en la elección, dada la gran cantidad de productos existentes en el mercado.

- La función de garantía de calidad del producto.

- La función de personalización que permite definir la identidad no solo del producto sino también del consumidor.

- La función lúdica, entendida como satisfacción o placer del consumidor en el acto de compra.

- La función práctica o de simplificación de la elección a la hora de comprar.

Desde los años ochenta, el universo de la marca ha experimentado cambios muy significativos que podemos resumir en tres puntos (Semprini, 1996b:53-60):

1. El giro del peso relativo de los términos producto-marca. La marca ha pasado a ser la auténtica protagonista y ha recubierto el producto con un envoltorio discursivo, comunicativo.

2. La entrada de la marca en el paradigma de la comunicación a través de un amplio muestrario de instrumentos y técnicas de las cuales la publicidad es solamente una de las manifestaciones posibles.

3. La construcción de una dimensión simbólica alrededor de la marca y del producto.

Actualmente las marcas han de proponer una estética, un estilo de vida e, incluso, una visión del mundo (Semprini, 1996b, 2006; Codeluppi, 2000). De hecho, el desgaste y agotamiento de los grandes relatos ha convertido la búsqueda de relatos ricos en sentido vital en una de las claves de lectura de nuestro tiempo (Nuñez, 2007). La crisis de los metarelatos activó la necesidad de buscar historias que dotaran de sentido (¿o de simulacro de sentido?) nuestras vidas, la vida. Poco a poco, se ha hecho evidente que las marcas ansiaban asumir esa función.

Como explica Christian Salmón (2007:57), "cuando se tiene un producto idéntico a otro producto hay diferentes medios para competir. $\mathrm{O}-\mathrm{y}$ ésta es la solución estúpida- se baja el precio, o se cambia el valor del producto contando su historia". Así las campañas publicitarias han pasado a ser secuencias narrativas a la búsqueda de sentido, para la marca y para los consumidores.

La marca se define por su triple naturaleza: la naturaleza semiótica, la naturaleza relacional y la naturaleza evolutiva o tendencia entrópica. Por naturaleza semiótica entendemos la capacidad de las marcas para elaborar y transmitir significados. La naturaleza relacional, en cambio, da cuenta de la capacidad de las marcas para relacionarse tanto con sus posibles compradores o seguidores como con sus competidores. Finalmente, la naturaleza evolutiva atiende al carácter dinámico y mutable de las grandes marcas. Además, en la postmodernidad, la marca ha adoptado la configuración de forma-marca, entendida como "una forma vacía, un formato y un proceso que pueden ser aplicados a cualquier manifestación o práctica social" (Semprini, 2006:228). La marca se ha ido transformando en un dispositivo general de 
organización y gestión de la discursividad social que "permite formatear el sentido, conferirle un valor y multiplicar la propia eficacia semiótica"(Semprini, 2006:252).

En el ámbito de las organizaciones no gubernamentales para el desarrollo, cabe recordar que entre 1985 y 1995 se produjo un aumento notable del número de organizaciones que propició un contexto de gran competitividad y, por ende, la necesidad de desarrollar estrategias de diferenciación. Cada ONGD se vio obligada a buscar un espacio propio dentro del tupido mundo de la cooperación y la ayuda humanitaria. Los mensajes publicitarios se multiplicaron, primero en prensa y radio, y - desde mediados de los noventa - en televisión. Poco a poco se intensificó la paradoja de querer ser "suficientemente diferentes pero parecer suficientemente iguales" (Atkin, 2005). Es decir, el esfuerzo de las ONGD por definir una identidad propia y, a la vez, mantener las similitudes con las otras organizaciones para poder ser reconocidas como organizaciones no gubernamentales para el desarrollo.

\section{Estudio de los logos}

Las manifestaciones de marca son múltiples y variadas. En estas páginas nos centraremos en los logos (entendidos como logosímbolos ${ }^{2}$ ) que son, sin duda, la puerta de entrada a cualquier marca. Como bien escribe Andrea Semprini (1993:96), un logo es "una clave de acceso inmediato o casi inmediato a la marca, que evoca la identidad de la marca por metonimia" (Semprini, 1993:96).

Veremos como en un logo se puede reconocer y avanzar $\neg-$ de manera sintética- la identidad visual de una marca, pero también su identidad narrativa y axiológica.

\subsection{Intermón Oxfam}

En el caso de Intermón Oxfam hemos podido diferenciar tres logos. El primero pertenece a los anuncios de los años 1988 y 1989. El nombre aparece en letras blancas minúsculas sobre un fondo negro o muy obscuro. La o es, a la vez, un globo terráqueo. Un símbolo que se repite en diversas ONGD. Los efectos de sentido que se derivan resultan obvios: Intermón es una organización de alcance mundial, preocupada por las personas necesitadas de cualquier lugar del planeta. El fondo de color negro puede connotar tanto seriedad y rigor, como dificultad del proyecto acometido.

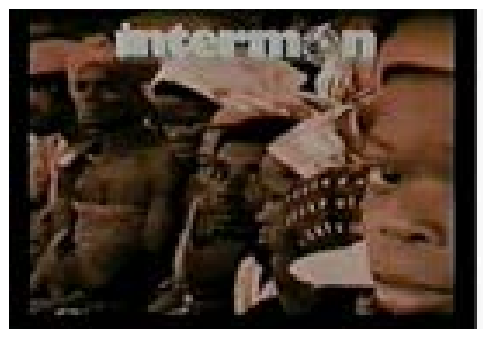

Intermón Oxfam. Logo 1 (1988)

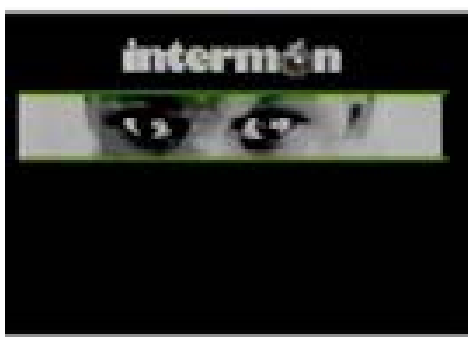

Intermón Oxfam. Logo 1 (1989)

2 "Es la denominación lógica correspondiente a la integración de logotipo [expresión visual de la denominación de la entidad] y símbolo [la parte no lingüística]”. Solas (2002), 100. 
El segundo logo pertenece a un anuncio del año 1994 titulado Grandes cosas. El primer cambio significativo es la desaparición del color negro, y el paso a la combinación verde y blanco. Debajo del nombre de la organización se puede leer: "Fundación para el Tercer Mundo". Y, desde 1999: "Miembro de Oxfam Internacional". De hecho Intermón pasó a denominarse Intermón Oxfam.

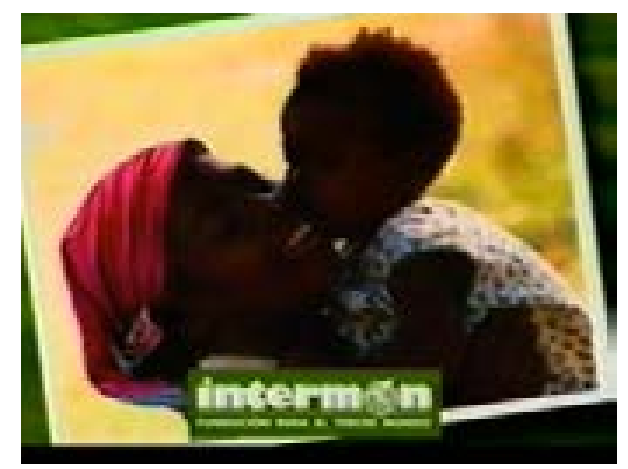

Intermón Oxfam. Logo 2 (1994)

Finalmente, el tercer logo aparece en un anuncio del año 2002. Supuso el primer paso hacia importantes cambios discursivos y narrativos que se concretaron en la campaña Soy $I O$, de 2003. En este tercer logo se mantiene el color verde pero se introduce un nuevo símbolo: un lazo de solidaridad, el eslabón de una cadena, que bien podría simbolizar la colaboración de sus socios y donantes con los pueblos más necesitados. La unión de los diferentes eslabones de la cadena hace la fuerza que necesita Intermón Oxfam para cambiar el mundo. El eslabón verde es un eslabón de solidaridad, de ayuda y de cooperación.
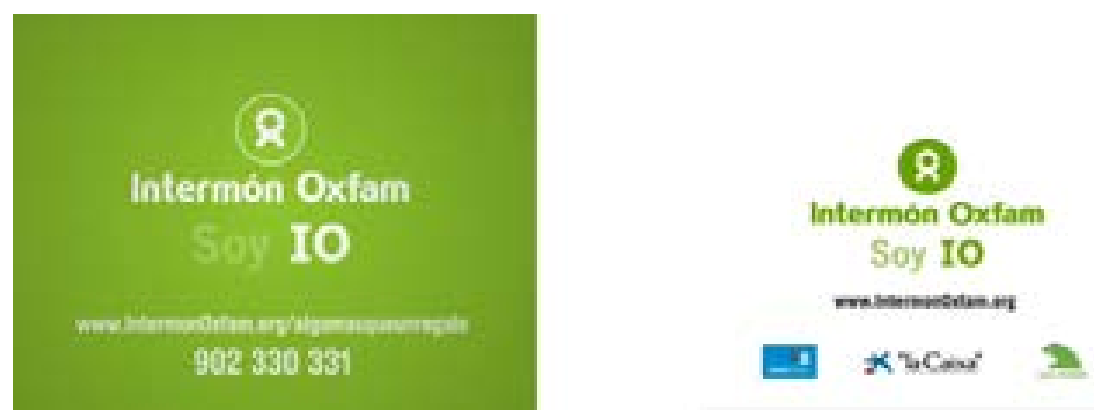

Intermón Oxfam. Logo 3 (2003)

Este cambio de logo llegó acompañado de una auténtica fractura discursiva y narrativa en la publicidad de Intermón. La nueva estrategia de (re)posicionamiento de marca se inició, como hemos apuntado, con el anuncio Soy IO (2003). El objetivo de la campaña era crear un relato basado en la identidad de los socios de Intermón, las 
llamadas "personas IO". Personas preocupadas por mejorar el mundo, personas que luchan por sus ideas, personas preocupadas por el prójimo. No olvidemos que hasta entonces los protagonistas de los anuncios habían sido las personas beneficiarias de la ayuda: los hombres, mujeres y niños del Tercer Mundo. Cabe destacar dos elementos que reforzaron el protagonismo innovador de los socios: la confluencia sonora "yo"/ "IO" del eslógan, y la utilización simbólica del espejo que se repitió en diversos anuncios de aquel año 2003 y de los años siguientes.

\subsection{Médicos sin fronteras}

En los anuncios de Médicos Sin Fronteras hemos podido diferenciar dos logosímbolos. El primero corresponde al periodo comprendido entre 1994 y 1998. La gamma cromática se limita a dos colores, el blanco y el negro. Colores asociados a la seriedad, la credibilidad, la estabilidad. En cuanto a los motivos figurativos, vemos una cruz y tres líneas en diagonal que simbolizan las fronteras a que se refiere el nombre de la organización. La cruz recuerda y, a la vez, se opone al símbolo de Cruz Roja. Es bien sabido que MSF nació como respuesta de un grupo de médicos franceses a ciertas deficiencias en la labor de CR durante el conflicto de Biafra (1968-1970), que es considerado el conflicto fundador de un nuevo humanitarismo, el humanitarismo sin fronteras (Duch, 2002). Por lo tanto, vinculación y ruptura de las dos organizaciones y de sus logos.

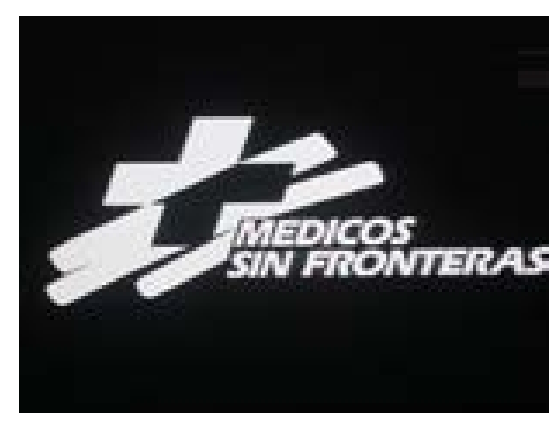

Médicos Sin Fronteras. Logo 1 (1994-1998)

En el segundo logo podemos constatar dos cambios significativos que despliegan renovados efectos de sentido.
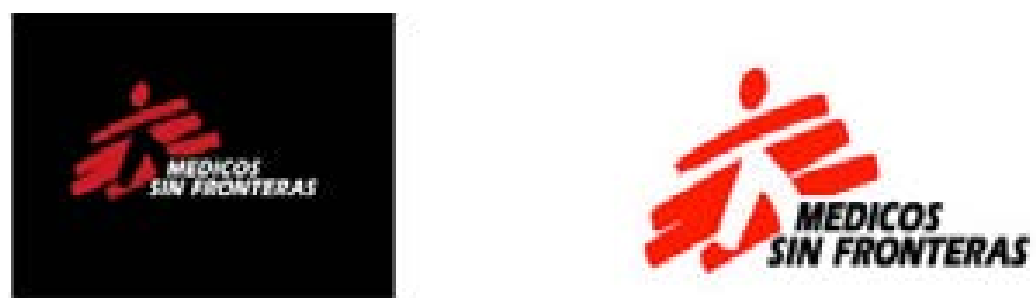

Médicos sin fronteras. Logo 2 (Desde 1999) 
Primero un cambio cromático, la utilización del color rojo, bien sobre fondo negro, bien sobre fondo blanco. Rojo y blanco son la metáfora cromática de la ayuda humanitaria desde la aparición de CR y de la Media Luna Roja, en la segunda mitad del siglo XIX.

Además, la cruz se antropomorfiza, se estiliza hasta convertirse en una figura humana atravesando las simbólicas líneas fronterizas. Se diría una evolución natural para diferenciarse de Cruz Roja, sin duda, la organización humanitaria de referencia internacional. El logo resulta extremadamente explícito y contiene las dos grandes aportaciones teóricas de MSF a la acción humanitaria: el protagonismo profesional y el sinfronterismo. Por un lado, hace referencia a unos profesionales de la salud encargados de hacer llegar la asistencia médica y humanitaria a todos aquellos que la necesiten, como decía, por ejemplo, un anuncio del año 2002: "Creemos que todas las personas tienen derecho a asistencia médica y humanitaria. Sean quien sean y estén donde estén. Para conseguirlo necesitamos tu colaboración todos los días del año".

Por otro lado, la idea clave del sinfronterismo afirma que se puede actuar en cualquier lugar del mundo sin pasar por la mediación del poder político e institucional, únicamente con la ayuda de los media y de la opinión pública, fomentando así una solidaridad de las emociones (Pech/Padis, 2004). De ahí que se haya acuñado la expresión "humanitarismo impulsivo" (Senarclens, 2000), que enaltece el activismo y que, en definitiva, expresa el individualismo radical del neoliberalismo dominante en las últimas décadas. La desmovilización política de las sociedades occidentales en las últimas décadas - tal vez, hasta la crisis económica actual - se concretaba en la movilización de las emociones y no de la reflexión política. "Podemos estar por encima de la política. Por encima del dinero. Por encima del poder. Si estamos juntos. Hazte socio de Médicos Sin Fronteras" ${ }^{4}$, decía un anuncio de los primeros años 2000.

\subsection{Ayuda en Acción}

Desde su primer anuncio de televisión (1995), Ayuda en Acción (AenA) ha utilizado tres versiones de su logo. El primero aparece en los anuncios de los años 1995, 1996 y 1997. El año 1999, la organización cambió de logo de manera muy significativa, buscando y encontrando efectos de sentido notablemente diferentes a los propuestos por el anterior. Este segundo logo se mantuvo hasta 2009 año en que experimentó una actualización, en esencia, cromática.

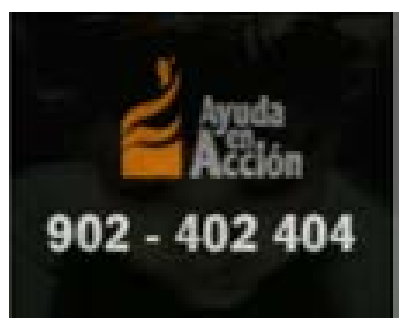

AenA. Logo 1 (1995)

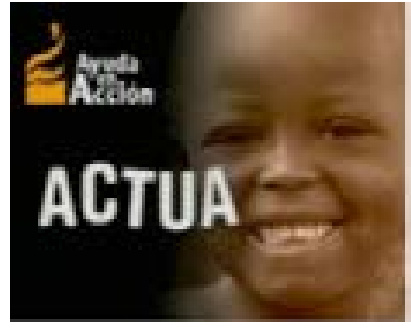

AenA. Logo 1 (1996)

\footnotetext{
3 Texto extraído del anuncio de televisión titulado Llamada (2002).

4 Texto extraído del anuncio de televisión titulado Por encima (2000-2001).
} 
El primero era un logo tricolor con un fondo negro, letras blancas y un símbolo de color naranja. El negro puede connotar tanto seriedad como negatividad, que podríamos relacionar con el dolor, la pena e incluso la muerte. En contraste, las letras son de color blanco, mientras que el símbolo utiliza el color naranja, tradicionalmente asociado al peligro y a las emergencias de todo tipo. El símbolo se asemeja a una llama que crece. De hecho, posibilita una doble lectura: tanto podríamos pensar en un amenaza, en un peligro creciente (inundaciones, terremotos, pandemias, sequía...) como en la ayuda invocada. La llama del peligro y, a la vez, la llama de la ayuda. El rectángulo de la base aporta estabilidad, terrenalidad pero tal vez también pesadez, falta de dinamismo, lentitud... E incluso, inexperiencia, inoperancia.

En cuanto a las letras, "ayuda" y "acción" aparecen como palabras separadas, situadas en dos niveles espaciales diferentes (arriba/abajo). Si tenemos en cuenta el tamaño diríamos que se insiste más en la acción que en la propia ayuda. Por otra parte, parece evidente la contradicción entre la pesadez del rectángulo basilar y el énfasis del termino acción.

Entre el anuncio de 1995 y el de 1996 hay una variación significativa en el último plano. En el año 1996 aparece la imagen partida, de manera que la parte derecha es ocupada por la cara de un niño negro muy sonriente que atenúa la negatividad del fondo negro anterior.

A partir de 1999 cambian las formas y con ellas los efectos de sentido. La llama desaparece y su lugar es ocupado por una mano abierta, blanca y muy estilizada, y por una flecha de retorno de un tono más rojizo que anaranjado (Nos Aldás, 2003). La mano abierta connota ligereza, actividad, dinamismo. La fecha, movimiento, actividad, acción. Frente a la pesada llama anterior, ahora las líneas ligeras, fuertemente estilizadas. La tipografía experimenta también cambios muy significativos: las dos "as" anteriores se convierten ahora en una gran y única "A" mayúscula. Una A que incluye "ayuda" y "acción". Por otra parte, la "y" ha experimentado una rotación visual, una licencia publicitaria que da mayor cohesión al conjunto y puede leerse como una metonimia visual de los beneficiarios que se apoyan en la ayuda y en la acción de la organización. Las letras han aumentado de tamaño y la tipografía se ha hecho más sólida, más visible.

El simbolismo de las nuevas formas resulta extremadamente explícito: la mano abierta es "colaboración", "ayuda", "cooperación". El recorrido de la flecha va desde ayuda hasta acción. La ayuda de los telespectadores es la acción de la onegé. La continuidad entre ayuda y acción se manifiesta tanto en la A compartida como en la dirección de la flecha. Los cambios apuntan a un mayor dinamismo, a una mayor eficacia. A mayor continuidad y experiencia.

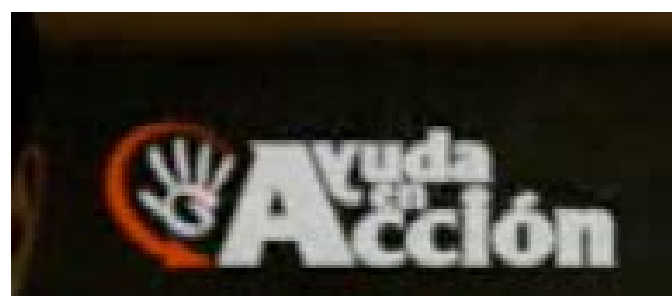

AenA. Logo 2 (1999-2008) 
Como hecho más llamativo, en el tercer logo desaparece el color negro. Además, cambian los colores tanto de la tipografía como de las imágenes. De manera que el blanco pasa a ser el color del fondo; el azul es el color de la mano y de las letras, resulta el color dominante y connota estabilidad, confianza, tranquilidad, integridad, seriedad. Finalmente, la flecha deja de ser roja para recuperar el naranja del símbolo inicial.
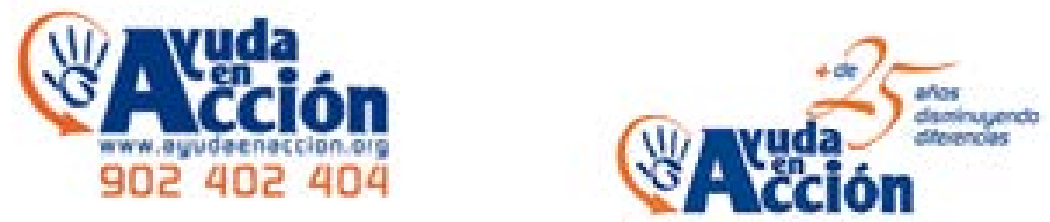

AenA. Logo 3 (2009)

La acción que se invoca desde el logo no es otra que el apadrinamiento de un niño del Tercer Mundo. Durante más de dos décadas ése ha sido el mensaje fundamental de Ayuda en acción. Podríamos recordar anuncios como Actúa (1999), Genios (2000), Niños perdidos (2001) o Creciendo juntos (2006). La ética i la estética de esta organización ha girado alrededor de la conocida fórmula: llámanos y apadrina un niño. Fórmula que, además, activa una transferencia de bienes simbólicos (dibujos, cartas, fotografías...) de los niños apadrinados hacia los donantes-padrinos.

\subsection{Anesvad}

Inicialmente, Anesvad fue el acrónimo de la expresión "A nuestros enfermos servimos viendo a Dios". Según información de la propia organización este significado se mantuvo hasta el verano de 2010 en que "la nueva dirección registró el nombre Anesvad como marca sin ningún significado"s. Desde los años noventa, esta organización se ha especializado en dos campos: las enfermedades tropicales desatendidas (lepra y úlcera de buruli) y la explotación sexual de menores en el sudeste asiático.

En el primer logo -años 1996 y 1997-, sobre el fondo blanco, se ve el símbolo en rojo y el nombre en negro. En la parte inferior, dentro de una cartela negra se puede leer, en letras blancas: "Acción sanitaria y desarrollo social". En cuanto a la tipografía, cabe destacar que todas las letras aparecen en mayúsculas y que la última "A", se alarga en la parte superior rompiendo así la uniformidad del conjunto y elevándose hacia las alturas, hacia el cielo, podríamos decir. La gama cromática se ajusta a los colores dominantes en los primeros logos de las organizaciones de nuestra muestra, eso es: blanco, negro y rojo.

${ }^{5}$ Información facilitada por Sandra Vázquez en correo electrónico del día 8 de enero de 2013. 


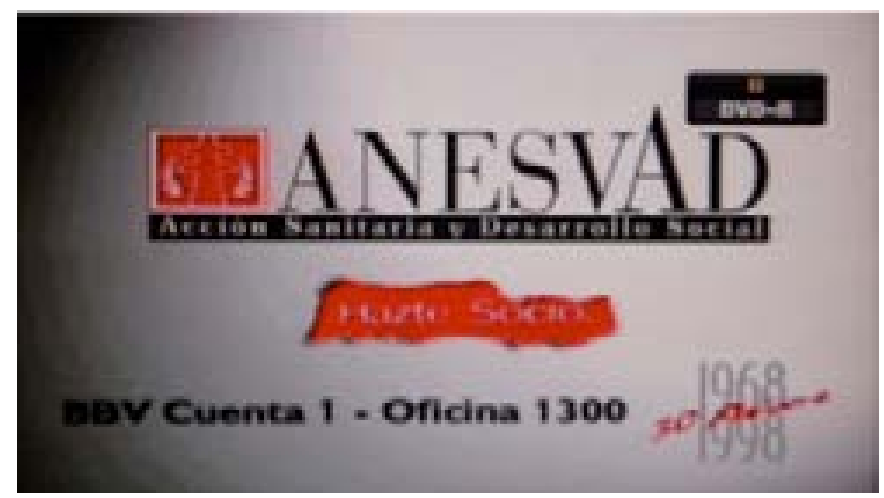

Anesvad. Logo 1 (1997)

El símbolo inicial fue una cruz patriarcal dibujada con finas líneas blancas sobre fondo rojo. Se trata de una cruz muy diferente a la utilizada por Cruz Roja o por el primer logo de Médicos Sin Fronteras, si bien con las mismas connotaciones de carácter religioso y sanitario. A ambos lados de la cruz, unas hojas de laurel, otro símbolo de larga tradición comúnmente relacionado con la celebración de una victoria. Se puede decir, además, que si, por un lado, las formas cuadradas y rectangulares pueden asociarse a la terrenalidad; del otro, las líneas compositivas (la A, la cruz y las ramas de laurel) apuntan, de forma complementaria, a la verticalidad.

El año 2003, en el anuncio Lavadora, Anesvad renueva plenamente su imagen visual, con cambios significativos tanto en lo referente a las figuras como a la tipografía y al cromatismo. El rojo, el blanco y el negro son sustituidos por el azul como color dominante. La tipografía combina las letras mayúsculas y minúsculas. Una figura de fuerte carga religiosa como la cruz es sustituida por una figura redonda que bien podríamos identificar simbólicamente con un globo terráqueo incompleto. El mundo se nos (re)presenta como un mundo fragmentado, imperfecto e inacabado que ha de ser apuntalado por la A de Anesvad. Las formas redondas se imponen, así como la horizontalidad frente a la verticalidad el primer logosímbolo. En amarillo una línea que, metafóricamente, podríamos identificar con el sol naciente, fuente de luz y de vida.

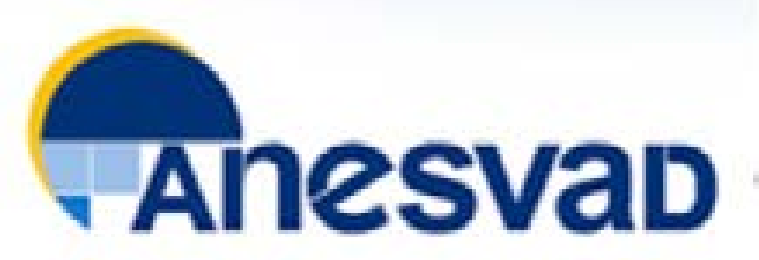

Anesvad. Logo 2 (Desde 2003) 
La historia de los logos de Anesvad resulta cuando menos paradójica. En el año 1998 - con el anuncio titulado Careta de Lady $D i$ - define una nueva estrategia publicitaria a la búsqueda de un posicionamiento claramente diferenciado respecto a las otras ONGD (Martínez Sánchez/Agüero, 2009). La nueva estrategia se basaba en la agresividad y la culpabilización directa y explícita de los teleespectadores, y en un estilo visual marcado por las imágenes hiperrealistas del cuerpo humano deformado por la lepra y la úlcera de Buruli, o en estridentes luces de neón y bruscos movimientos de cámara. Sirvan de ejemplo anuncios como Progresividad I, II, III (1999), Prótesis (2000), Agua hirviendo (2000) o Sin sonido (2003). La agencia encargada de crear esta nueva imagen de marca fue Remo\&Asatsu, que realizó todos los anuncios de Anesvad de 1998 a 2005. Sin embargo, se mantuvo el logo de la etapa anterior hasta 2003, año en que el cambio de logo quiso asociarse a la suavización de sus mensajes publicitarios. Lavadora nos permite corroborar, por el contrario, que se trató de un intento fallido.

Después de casi tres años sin publicidad debido a los problemas judiciales ${ }^{6}$ de la organización, la campaña Creemos que es posible (2009) significó un cambio radical a nivel discursivo, narrativo y axiológico. En el anuncio de presentación de la campaña ${ }^{7}$, la Fundación Anesvad decía: "Después de unos años sin hacer publicidad, Anesvad decide cambiar el tono de su comunicación. El reto consistía en pasar de un tono crudo a un tono más esperanzador y positivo". De nuevo paradójicamente, la transformación general de la comunicación publicitaria de Anesvad no fue acompañada de un cambio de logo, que se ha mantenido idéntico al de los años 2003-2006 aunque acompañado de un texto explicativo: "Trabajamos para promover y proteger el derecho a la salud".

Renovación sí, pero con continuidad de la marca ya creada .

\section{5. África Directo}

En el logosímbolo de África Directo se utilizan solamente dos colores: el blanco y el negro. Por tanto, podríamos hablar de ausencia de color como primer elemento diferenciador, que genera, además, efectos de sentido muy precisos. Por un lado, el blanco y el negro adquieren una connotación positiva como metáfora cromática de la seriedad, del rigor y la austeridad. Contrariamente, el color significaría, en este contexto, superficialidad, frivolidad, falta de eficacia y gastos adicionales. Falta de color entendida como falta de gastos innecesarios o inútiles. Es decir, como ausencia de distracciones del trabajo real encomendado a la organización por sus socios y donantes. Se trata, pues, de una selección cromática de carácter fundamentalmente axiológico.

En cuanto a las formas y los motivos utilizados, aparecen únicamente dos caras, de perfil y sobre fondo blanco. Una cara negra, en la parte superior que es ligeramente más amplia. Y una cara blanca, en primer término, más estrecha. Metonímicamente, la cara blanca es la representación de los donantes, de igual manera que la cara negra representa a los receptores de la ayuda.

${ }^{6}$ El año 2007 Anesvad fue sometida a una investigación judicial que terminó con la detención de su presidente, José Luis Gamarra, acusado de desviación y apropiación de fondos. Anesvad fue intervenida en el mes de octubre de aquel mismo año.

${ }^{7}$ http://www.youtube.com/watch?v=AzZOd0J56eE. 
Se utilizan solamente letras minúsculas y un punto final, que tiene una forma idéntica a los puntos que representan los ojos de las caras, exactamente al ojo de la cara blanca. Las letras minúsculas se han de relacionar también con la austeridad, a la reducción a la mínima expresión de todo lo que no sea esencial.

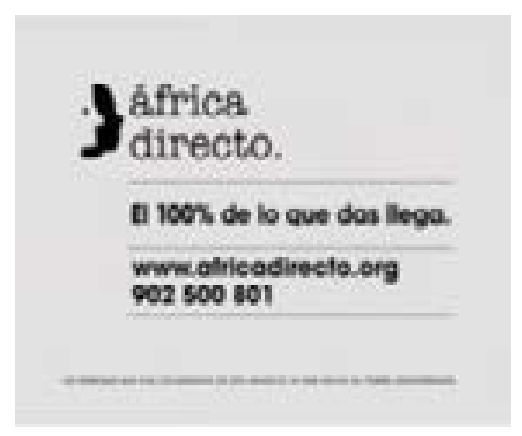

África Directo. Último plano de $4 x 4$

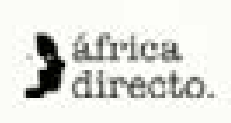

mww africadirecto org

$\$ 2 \$ 00001$

En definitiva, cabe hablar de esquematismo cromático y figurativo. Todo -tipografía, figuras y colores-parece estar en consonancia con el adjetivo de la propia denominación: "directo". Es decir, derecho, recto, sin intermediarios, inmediato. Y también, sencillo, sin retórica alguna. Así, la ausencia de color, las letras minúsculas, el esquematismo de las formas se corresponde con la sencillez, la austeridad defendida por la organización y adquiere un valor simbólico al evocar la falta de gastos innecesarios y, en consecuencia, la eficacia, el rigor, la franqueza.

En conclusión, los efectos de sentido buscados por el logo de África Directo son simplificación máxima, sencillez, falta de artificio y falta de intermediarios. Los relatos construidos en anuncios como $4 x 4$ (2005), Publicidad (2007) y Voluntaria (2010) confirman esas intenciones.

\section{Conclusión}

En las páginas anteriores hemos estudiado el posicionamiento de marca de cinco grandes ONGD a través de sus logos, y hemos podido constatar:

1. Que la transformación de las ONGD hacia los planteamientos de marca arrancan de mediados de los años noventa con la apertura de las grandes ONGD a la comunicación publicitaria masiva.

2. Que el logo construye, en buena medida, la identidad visual de una marca y anticipa sus principales relatos y sus valores fundadores.

En nuestro análisis de los logos de Intermón Oxfam, Médicos Sin Fronteras, Ayuda en Acción, Anesvad y África directo hemos considerado tanto la selección cromática como la selección figurativa. La selección cromática nos ha permitido seguir la evolución de cada una de las organizaciones: desde la preferencia inicial por el negro (IO, MSF, AenA) a la diferenciación a través del color a partir de los años noventa. En 1994 Intermón apostó por el verde. MSF pasó del negro al rojo en el año 1999. Ayuda 
en Acción ha ido combinando, desde finales de los noventa, el rojo, el blanco y el azul. En el caso de Anesvad, diremos que durante décadas utilizó el rojo y el blanco, pero que a partir de 2003 empezó a utilizar una combinación de azul, amarillo y blanco. Finalmente, África Directo optó por el no color, es decir, por la austeridad del blanco y el negro.

También, la selección figurativa ha seguido una clara evolución hacia la diferenciación de marca. Intermón abandonó en 2003 el globo terráqueo y empezó a utilizar el lazo solidario. MSF convirtió la cruz inicial en una figura humana cruzando una minimalista, simbólica y particular frontera. Ayuda en Acción pasó de la llama a la mano abierta como representación de la actuación de la organización y de sus donantes. Anesvad eliminó la cruz patriarcal y apuntaló la bola del mundo. África Directo, para acabar, optó por la simetría/disimetría de dos caras, una blanca y la otra negra. El donante y el receptor de la ayuda.

El caso más paradójico es, sin duda, el de Anesvad. La doble renovación de los mensajes de la organización en 1998 y en 2009 no fue acompañada, como cabía esperar, de un cambio de logosímbolo.

El análisis desarrollado nos ha permitido, además, anticipar los principales relatos de posicionamiento de marca de las ONGD estudiadas. Relatos caracterizados por su fuerte carga de sentido vital que vendría a paliar la desconfianza creciente en la sociedad española de los noventa en la política, los sindicatos, o la religión... y en sus metarelatos que habían cohesionado la sociedad en las décadas anteriores.

En su primer logo, Intermón apuntaba hacia la utopía pedagógica universal, es decir, a aquello que, de manera explícita, proclamaban los anuncios de la primera mitad de los años noventa: enseñar a pescar, enseñar a cultivar la tierra, enseñar a leer... A partir de 2003, esta organización se reposicionó como marca que pretendía celebrar y reivindicar la identidad solidaria y comprometida de sus socios y donantes. El nuevo logo inauguró un nuevo relato que transfería los valores anteriormente asociados a la organización (altruismo, compromiso, solidaridad) a sus colaboradores.

Médicos Sin Fronteras no ha cambiado su valor fundador: la utopía sanitaria universal. Pero, el cambio del logo, en 1999, reforzó su condición de organización profesional y anticipó los relatos épicos protagonizados por médicos y profesionales sanitarios.

Desde su creación, Ayuda en acción colocó el apadrinamiento de niños del Tercer Mundo en los fundamentos de su trabajo, y lo presentó como la solución a la pobreza en el mundo. Por eso, durante décadas, sus anuncios han sido protagonizados por niños abandonados, niños hambrientos, niños enfermos... o por los niños apadrinados, y por sus padrinos.

Anesvad se ha especializado en las enfermedades tropicales desatendidas (lepra y úlcera de Buruli) y en la explotación sexual infantil en el sudeste asiático. En los noventa no dudó en difundir relatos abiertamente tremendistas e inculpatorios que hacían caer la responsabilidad de la situación en los lectores o espectadores de sus anuncios. Su campaña Creemos que es posible (2009), rompió esa línea y resultó un relato de refundación paradigmático. 
Finalmente, $\mathrm{AD}$, la onegé de fundación más tardía, buscó su lugar en el espeso campo de la solidaridad reivindicando como valores esenciales la honestidad y la austeridad en la redistribución de fondos. La elección del propio nombre subraya diafanamente la ambición de la organización por situarse -al menos, discursivamente- en un nivel de compromiso y de eficacia máxima que pueda diferenciarla del resto de marcas ONGD.

Douglas Atkin ha señalado como función clave de las marcas el hecho de saber "gestionar diestramente la tensión entre ser suficientemente diferentes, pero parecer suficientemente similares" (Atkin, 2005:184). Es un buen resumen del esfuerzo de cada una de las ONGD estudiadas por ser reconocidas como ONGD y, a la vez, poder diferenciarse del resto de estas organizaciones. Saber administrar, eficazmente, la paradoja de querer ser diferentes e iguales. Iguales y diferentes al resto de organizaciones y a ellas mismas dado que la naturaleza entrópica de la marca exige una redefinición constante. Estabilidad y evolución. O sea, evolución pero sin traicionar la marca ya construida.

La forma-marca ha formateado el sentido de los mensajes de las grandes ONGD de difusión masiva en las últimas décadas. Lo ha hecho de una manera altamente persuasiva y eficaz en lo que se refiere a la implantación y crecimiento de las propias organizaciones. Cabe señalar, sin embargo, que su eficacia ha sido escasa en el objetivo de acabar con la pobreza y el hambre en el mundo. Eso podríamos colegir, por ejemplo, de la crisis alimentaria del año 2008, de las campañas para paliar la hambruna en el Sahel en 2012, o del último informe del Programa de Naciones Unidas para el Desarrollo (enero 2014) que afirmaba que el $75 \%$ de la población mundial vive hoy en sociedades donde la desigualdad en la distribución de la renta es mayor que hace dos décadas. Eficacia comunicativa, pero ineficacia en cuanto a la transformación de la realidad.

\section{Bibliografía}

AtKIN, D. (2005): El culto a las marcas. Cuando los clientes se convierten en creyentes, Barcelona, RobinBook.

Codeluppi, V. (2008): "La marca entre empresa y sociedad", Pensar la publicidad. Revista Internacional de Investigaciones Publicitarias, Vol. II, 1, 37-44.

- (2001): Il potere della marca. Disney, McDonald's, Nike i le altre, Torino, Bollati Boringhieri.

- (2000): "Verso la marca relacionale". Convegno Le tendenze del marketing in Europa. Università Ca' Foscari. Venezia, 24 novembre 2000.

Duch, P. (2002): 30 años de sinfronterismo: Una reflexión de futuro.

http://www.barcelona.msf.org/sites/default/files/publicacion/cuaderno17.pdf

FlOCH, J.M. (1994): "La voie des logos. Approche sémiotique des logos IBM et Apple",

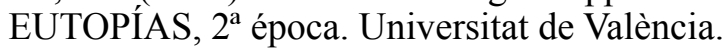

- (1991): Semiótica, marketing y comunicación. Bajo los signos, las estrategias, Barcelona, Paidós, 1993.

Gómez GIL, C. (2005): Las ONG en España. De la apariencia a la realidad, Madrid, Los libros de la Catarata.

GonzÁlez Solas, J. (2002): Identidad Visual Corporativa. La imagen de nuestro tiempo, Madrid, Síntesis. 
Lucerga Pérez, M. J. (2005): "Cuando IO soy la marca. La solidaridad como construcción publicitaria", TONOS. Revista electrónica de estudios filológicos, 9. http://www.um.es/tonosdigital/znum9/estudios/ongtonos.htm

Martínez SÁnchez, J.l. /Agüero, A. (2004): "La política de comunicación en ANESVAD", Madrid, Departamento de Publicaciones del IE. Business School.

Nos AldÁs, E. (2007): Lenguaje publicitario y discursos solidarios. Eficacia publicitaria, ¿eficacia cultural?, Barcelona, Icaria.

- (2003): "Discurso publicitario y sensibilización en las ONGD: de la función social de la publicidad a la responsabilidad de la comunicación social" en BENET V. J. I Nos, E. (ed), La publicidad en el Tercer Sector, Barcelona, Icaria.

NuÑEz, A. (2008): iSerá mejor que lo cuentes. Los relatos como herramienta de comunicación, Barcelona, Urano.

Pech, T./Padis, M.o. (2004): Le multinazionali del cuore, Milano, Feltrinelli.

SABAtÉ, J. (2003): "El mercado de la solidaridad" en Anuncios, núm. 995. Madrid.

Saiz EchezArReta, V. (2009): La solidaridad, espacio de mediación de los sentimientos morales: análisis de la publicidad de las ONGD. Tesi Doctoral dirigida per Cristina Peñamarín Beristain. Universidad Complutense de Madrid. Departament de Ciencias de la Información. http://eprints.ucm.es/10737/

Salmon, C. (2008): Storytelling. La máquina de fabricar historias y formatear las mentes, Barcelona, Península.

Santolino Prieto, M. (2011): "Recuperando la esencia: las ONGD como agentes de comunicación para el cambio social" en Comunicando para la solidaridad y la cooperación. Cómo salir de la encrucijada, Barcelona: Foro Comunicación, Educación y Ciudadanía.

SEMPRINI, A. (2006): La marca postmoderna. Potere e fragilità della marca nelle società contemporanee, Milano, FrancoAngeli.

- (2003): "Il linguaggio della marca" en Lo sguardo sociosemiotico. Comunicazione, marche, media, pubblicità, Milano, Franco Angeli. [1999]

- (1996a): "Benetton: Histoire d'un scandale annonce" en Analyser la communication. Comment analyser les images, les médias, la publicité, París, L'Harmattan.

- (1996b): La marca dal prodotto al mercato, dal mercato a la società, Milan, Lupetti. semprini.fr/page15/page16/files/La\%20marca.pdf

- (1993): Marche e mondi possibili. Un approccio semiotico al marketing della marca, Milano, Franco Angeli.

- (1992). Le marketing de la marque. Approche sémiotique, París, Editions Liaisons.

Senarclens, P. (2000): La acción humanitaria ante las catástrofes. Barcelona, Bellaterra. 